Brief Report

\title{
Survival of SARS-CoV-2 on Non-Porous Materials in an Experimental Setting Representative of Fomites
}

\author{
Laura Bonil $^{1}$, Guillaume Lingas ${ }^{2}$, Damien Coupeau ${ }^{1}\left(\mathbb{D}\right.$, Jean-Christophe Lucet ${ }^{2,3}$, Jérémie Guedj ${ }^{2} \mathbb{D}$, \\ Benoît Visseaux ${ }^{2,4, *(D)}$ and Benoît Muylkens ${ }^{1}$
}

1 Namur Research Institute for Life Sciences (NARILIS), Integrated Veterinary Research Unit (URVI), Université de Namur, 61 rue de Bruxelles, 5000 Namur, Belgium; laura-alejandra.rubiano@unamur.be (L.B.); damien.coupeau@unamur.be (D.C.); benoit.muylkens@unamur.be (B.M.)

2 Institut National de la Santé et de la Recherche Médicale (INSERM) UMR 1137, Infection Antimicrobials Modelling Evolution (IAME), Université de Paris, 75018 Paris, France; guillaume.lingas@inserm.fr (G.L.); jean-christophe.lucet@aphp.fr (J.-C.L.); jeremie.guedj@inserm.fr (J.G.)

3 Infection Control Unit, Publique-Hôpitaux de Paris (AP-HP), Bichat-Claude Bernard University Hospital, 46 rue Henri Huchard, 75018 Paris, France

4 Department of Virology, Publique-Hôpitaux de Paris (AP-HP), Bichat-Claude Bernard University Hospital, 46 rue Henri Huchard, 75018 Paris, France

* Correspondence: benoit.visseaux@aphp.fr; Tel.: +33-1-4025-6152

Citation: Bonil, L.; Lingas, G.; Coupeau, D.; Lucet, J.-C.; Guedj, J.;

Visseaux, B.; Muylkens, B. Survival of SARS-CoV-2 on Non-Porous Materials in an Experimental Setting Representative of Fomites. Coatings 2021, 11, 371. https://doi.org/ 10.3390/coatings11040371

Academic Editor: Ajay Vikram Singh

Received: 16 February 2021

Accepted: 18 March 2021

Published: 24 March 2021

Publisher's Note: MDPI stays neutral with regard to jurisdictional claims in published maps and institutional affiliations.

Copyright: (c) 2021 by the authors. Licensee MDPI, Basel, Switzerland. This article is an open access article distributed under the terms and conditions of the Creative Commons Attribution (CC BY) license (https:// creativecommons.org/licenses/by/ $4.0 /)$.

\begin{abstract}
To better understand plausible SARS-CoV-2 transmission through fomites, a physiological model was designed to analyze the decay rate of SARS-CoV-2 infectivity. We focused on non-porous materials present in high-touch surfaces or used as containment barrier surfaces, namely glass, acrylic glass, photo-activated coated glass, stainless steel and aluminium. SARS-CoV-2 survival depended on the material considered, with half-lives on glass, photo-activated coated glass, stainless steel and aluminium equal to $6.9,4.1,3.5$ and $2.3 \mathrm{~h}$, respectively. This study highlights the potential utility of coatings in the fight against the current threat. In addition, it spotlights the need for standardizing assays to assess indirect transmission of COVID-19.
\end{abstract}

Keywords: SARS-CoV-2; stability; persistence; fomites; non-porous materials; glass; stainless steel; aluminium; photo-activated glass

\section{Introduction}

As with several respiratory viral pathogens, the coronavirus transmission path occurs through direct or indirect contact between infected individuals or contaminated fomites and naïve individuals. Respiratory droplets and aerosols are proposed to represent the source of contamination [1,2]. Transmission could occur when the infected person speaks, coughs, sneezes, sings, or undergoes medical procedures [3]. Understanding the transmission routes is critical for designing, applying, and evaluating prevention and control measures. In that perspective, efforts should tackle the problem at the source and propose new measures to mitigate the rapid spreading of SARS-CoV-2 [4].

To date, several studies were published analyzing the persistence of SARS-CoV-2 on various surfaces, which act as fomites, showing that the virus remains infectious for a longer time in non-porous materials and in settings with lower temperature and humidity [2,5-8]. In a first report, van Doremalen and collaborators [2] assessed SARS-CoV-2 stability on various porous and non-porous materials. In this pioneer study, virus infectivity was still detected for up to $72 \mathrm{~h}$ on plastic and stainless steel. Following this initial description, different settings were developed to evaluate SARS-CoV-2 stability. For the same material, a huge range of decay times was reported. For example, viral infectivity was detected from 3 up to 28 days when tested on stainless steel [2,7]. The high degree of discrepancies might originate from assessments based on different inoculum with varying viral loads, droplet sizes and matrix compositions. Stabilization of viral infectivity was observed when 
the virus was suspended in complex matrices with enriched protein concentration $[5,7]$. Another discussion arises from studies where SARS-CoV-2 fomites contamination was evaluated through the quantification of the viral RNA load without testing the associated viral infectivity $[9,10]$. In the present assay, we selected a viral inoculum suspended in small droplets within a matrix corresponding to average extra-cellular medium. This inoculum contained a viral concentration representative of the average viral load found in a large cohort of SARS-CoV-2 infected patients [11] and was analyzed in a model which compiles viral genomic load and viral infectivity data over time.

This model was applied to evaluate viral stability on innovative materials. In this context, coatings are considered as potential tools to mitigate indirect transmission of SARS-CoV-2. These coated materials open the opportunity of responding to the urgent global call to integrate different branches of knowledge to develop, analyze and implement practical and feasible solutions [12]. Significant efforts evaluating the efficiency of antiviral technology-based materials and coatings have been made [13]. Several viral stability studies have been published which investigated surfaces; the use of titanium dioxide was examined: $\mathrm{TiO}_{2}$ thin films were deposited with different processes, for example, using the spin-coating method [14], using the spray adhesion method [15], and by immersion in $\mathrm{TiO}_{2}$ nanosized particles suspension [16]. In opposition with these post-manufacturing coatings in the form of $\mathrm{TiO}_{2}$ thin films or $\mathrm{TiO}_{2}$ nanoparticles, an original material was tested here, where $\mathrm{TiO}_{2}$ is immobilized in the upper layer of glass during manufacturing. The coating is strongly bonded to the glass surface and is considered a continuous sublayer in parallel to the glass surface.

In the present study, the risk associated with contaminated droplets was evaluated in experimental laboratory settings, where contaminated objects were sorted according to their capacity to decrease viral infectivity. Properties of inanimate objects were thoroughly assessed in order to discriminate materials that either permit or prevent SARS-CoV-2 transmission. To this end, maintenance of viral infectivity was measured over time following SARS-CoV-2 controlled exposures of inert materials that might be used as a screen in a daily environment to impair the viral transmission, such as glass, acrylic glass, stainless steel, aluminium and titanium dioxide coated glass with photocatalytic properties.

\section{Materials and Methods}

\subsection{Inert and Activated Non-Porous Materials}

The surface materials used as inoculum carriers were clear soda-lime glass (classic glass), polymethyl methacrylate acrylic (acrylic glass), aluminium alloy (AW-6082), stainless steel 304, and float glass coated with a pyrolytic coating sublayer of $\mathrm{TiO}_{2}$ deposed in its crystalline anatase form by chemical vapor deposition (CVD). The carriers with coating complied with class A mechanical and chemical durability tests required in the European standard EN1096-2:2012 [17] (Planibel Easy). $\mathrm{TiO}_{2}$-based carriers were irradiated with UVA 340 lamps for $4 \mathrm{~h}$, corresponding to one daylight (photo-activated $\mathrm{TiO}_{2}, \mathrm{PA}+\mathrm{TiO}_{2}$ glass). Inoculum droplets were poured on the coated glass surface $1 \mathrm{~h}$ post-irradiation. No additional UV exposure was applied thereafter, excluding any direct UV light impact on viral particles. The lamps provide a close simulation of sunlight in the critical short wavelength region from $365 \mathrm{~nm}$ down to the solar cut-off of $295 \mathrm{~nm}$. At $340 \mathrm{~nm}$, corresponding to emission peak, the irradiance is $0.68 \mathrm{~W} / \mathrm{m}^{2}$ which is equivalent to noon summer sunlight. Some other $\mathrm{TiO}_{2}$-based carriers were not irradiated as reference (non photo-activated $\mathrm{TiO}_{2}$, $\mathrm{PA}-\mathrm{TiO}_{2}$ glass).

\subsection{Experimental Settings}

Room temperature and relative humidity were set at $22{ }^{\circ} \mathrm{C}$ and $54 \%$ respectively. The following critical parameters were fine-tuned to enable a better viral decay in the surface-liquid contact interphase. (i) Each material carrier was inoculated by pouring 5 droplets of $4 \mu \mathrm{L}$ of Eagle's Minimum Essential Medium (EMEM) containing 1\% fetal bovine serum (for a total volume of $20 \mu \mathrm{L}$ ), also containing a (ii) viral load of 5000 Tissue 
Culture Infectious Dose 50\% (TCID 50 ), reflecting the median genomic viral load observed in a cohort of 1400 patients screened at the University of Namur in 2020 March and April [11]. (iii) Immediately after viral inoculation and at 2, 4, 6, 12 and $24 \mathrm{~h}$ post-inoculation, the remaining inoculum was recovered by immersion of each material carrier with $1 \mathrm{~mL}$ of EMEM. The decay rate of SARS-CoV-2 was measured in independent triplicates.

The Vero E6 cell line was used to determine the infectious virus concentration by an endpoint dilution assay. The cytopathic effect was assessed and count on the 96 well plates (6 replicates by dilution), and the titers displayed as $\mathrm{TCID}_{50} / \mathrm{mL}$, according to the Reed and Muench method. The limit of detection corresponds to $20 \mathrm{TCID}_{50} / \mathrm{mL}$. In parallel, RNA was extracted from each corresponding surface elute to detect and quantify viral genomic load by RT-qPCR targeting SARS-CoV-2 E gene as detailed in [11]. Briefly, reverse transcription was realized ahead of the amplification step targeting E gene locus by using adapted primer pairs and probe. An internal control permitted validating the results.

\subsection{Statistical Analysis}

A mechanistic model was developed to fit both TCID $_{50}$ and RT-qPCR kinetics. We assumed that virus concentration per $\mathrm{mL}, \mathrm{V}$, as measured by RT-qPCR, was the sum of infectious and non-infectious particles concentrations per $\mathrm{mL}$, noted $\mathrm{V}_{\mathrm{I}}$ and $\mathrm{V}_{\mathrm{NI}}$, respectively, and we assumed that $1 \mathrm{TCID}_{50}$ corresponded to approximately 1 infectious virus. The total amount of virus was assumed to decline with rate $c$ (for example, the viral halflife is $\log (2) / \mathrm{c}$ ) and the virus was assumed to lose infectivity with rate $\rho$ (for example, the infectious virus half-life is $\log (2) / \rho)$. Thus, in this model, the kinetics of total and infectious virus was given by $\mathrm{V}(\mathrm{t})=\mathrm{V}_{0} \times \exp (-\mathrm{c} \times \mathrm{t})$ and $\mathrm{V}_{\mathrm{I}}(\mathrm{t})=\pi \times \mathrm{V}_{0} \times \exp (-(\mathrm{c}+\rho) \times \mathrm{t})$, respectively, where $\pi$ is the proportion of infectious virus in the initial inoculum noted $V_{0}$. Parameters were fitted to all replicates simultaneously, using a mixed effect modelling approach and the SAEM [18] was implemented in Monolix software 2020R1 (www.lixoft.com, accessed on $06 / 11 / 2020$ ).

To compare the decline rates in the different materials, the following procedure was used. First, the model was fitted, assuming all materials were different. A forward strategy was then used to assess the possibility of different group surfaces. Materials were grouped one by one and were kept grouped if the resulting Bayesian information criterion, a statistical criterion derived from the likelihood of the model that considers the number of estimated parameters as well as the number of observations, did not decrease by more than 2 points [19]. The procedure was continued until no improvement of the Bayesian information criterion was obtained. Finally, the significance of differences in the parameters in the different surfaces were tested using the Wald test, which uses the estimated residual standard error of the estimated coefficient associated with the covariate to estimate the test statistics. When the final model was obtained, we used the individual parameters to simulate the viral load dynamics predictions. We calculated the predicted median times needed to decrease the infectious viral load by $90 \%$ from baseline and reach the level of $3 \log 10 \mathrm{TCID}_{50} / \mathrm{mL}$.

\section{Results}

Total RNA viral load remained stable over time, with a minimal decay rate of $4 \times 10^{-3} \mathrm{~h}^{-1}$, corresponding to a half-life of $172 \mathrm{~h}$ and no differences across materials. Before constituting groups of material, the loss rates of infectivity were estimated as $0.1,0.1,0.11,0.16,0.20$, and $0.29 \mathrm{~h}^{-1}$, respectively, for classic glass, acrylic glass, non photo-activated $\mathrm{TiO}_{2}$ glass, photo-activated $\mathrm{TiO}_{2}$ glass, stainless steel and aluminum. In the final model, the classic glass, the acrylic glass and the non-activated $\mathrm{TiO}_{2}$ treated glass had no significant differences in the loss rate of virus infectivity, with a rate of $0.1 \mathrm{~h}^{-1}$, corresponding to a half-life of the infectious virus of $6.9 \mathrm{~h}$, and were therefore considered as a single reference surface in the rest of the analysis, Figure 1. 


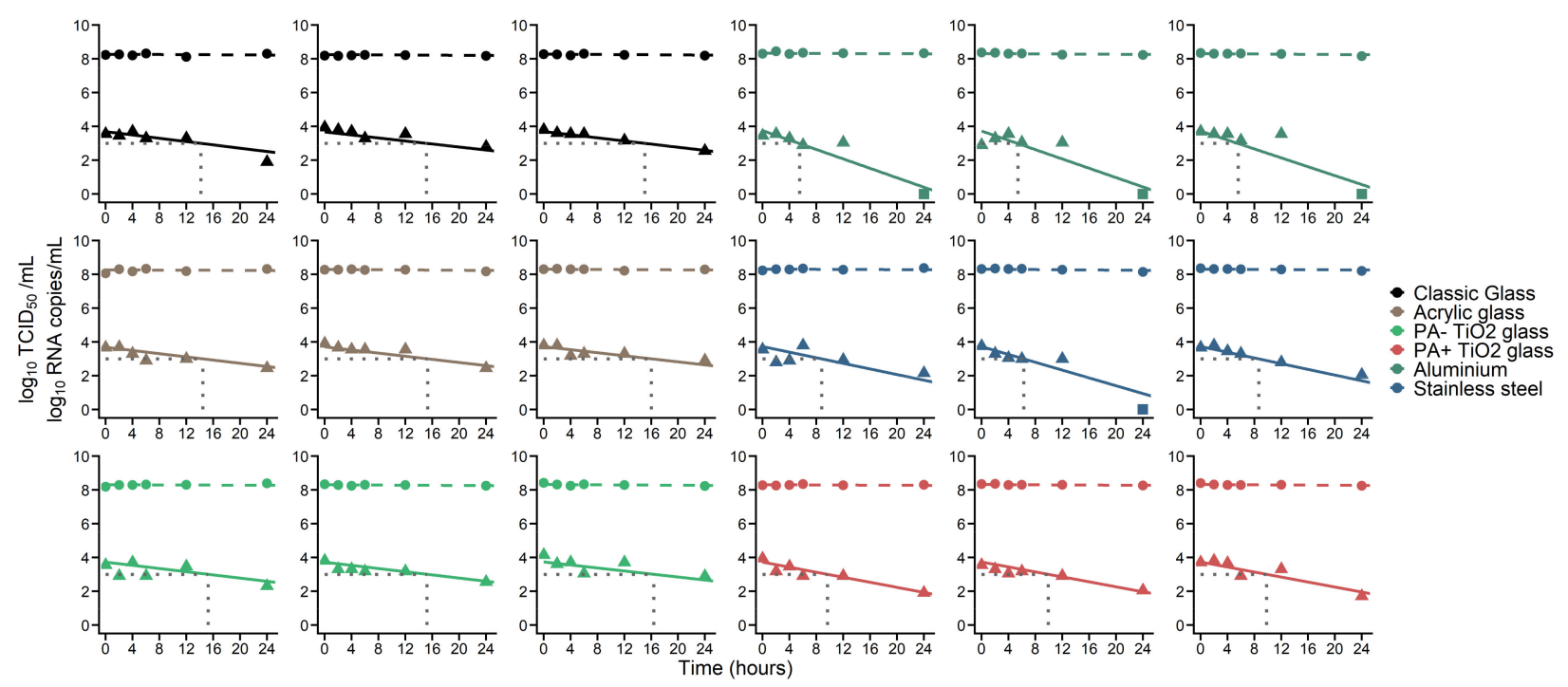

Figure 1. Individual fits of RNA and TCID $_{50}$ data. Dashed lines represent fits of RNA viral load data (circles). Plain lines represent fits of $\mathrm{TCID}_{50}$ data (triangles). Squares represent TCID50 data under the limit of quantification. Dotted lines indicate the point the time at which $\mathrm{TCID}_{50}$ reaches $3 \log 10 / \mathrm{mL}$.

In contrast, infectious virus decreased more rapidly in contact with photo-activated $\mathrm{TiO}_{2}$ coated glass, with a loss rate of $0.16 \mathrm{~h}^{-1}$ corresponding to a half-life of $4.1 \mathrm{~h}(p=0.006$ to reference surfaces, that is, classic glass, acrylic glass and non photo-activated $\mathrm{TiO}_{2}$ glass). This loss rate was even more significant on stainless steel and aluminium, with values of 0.2 and $0.3 \mathrm{~h}^{-1}$ respectively, corresponding to half-lives of 3.5 and $2.3 \mathrm{~h}$ (both $p<10^{-4}$ to reference surfaces). Using this model, we predicted that the time to decrease infectivity by $90 \%$ was shortened in aluminium, stainless steel and photo-activated $\mathrm{TiO}_{2}$ treated glass by $66.2 \%, 44.6 \%$ and $37.5 \%$ compared to reference surfaces $(7.3,11.9$ and $13.5 \mathrm{~h}$ vs. $21.6 \mathrm{~h}$, respectively). Similar trends were obtained for the time needed to reach $3 \log 10$ TCID50/mL, with values of $15.2,9.8,8.7$ and $5.5 \mathrm{~h}$ for reference surfaces, photo-activated $\mathrm{TiO}_{2}$, stainless steel and aluminium, respectively, Table 1.

Table 1. Estimated parameters of the infective virus dynamics.

\begin{tabular}{|c|c|c|c|}
\hline Material & Half-Life (h) & $\begin{array}{c}\text { Time to } 90 \% \text { Decrease of } \\
\text { TCID }_{50} \\
\text { (Median, } h \text { ) }\end{array}$ & $\begin{array}{l}\text { Time to Reach } \\
1000 \text { TCID }_{50} / \mathrm{mL} \\
\text { (Median, h) }\end{array}$ \\
\hline \multicolumn{4}{|l|}{ Classic glass } \\
\hline Acrylic glass & $6.9^{1}$ & 21.6 & 15.2 \\
\hline \multicolumn{4}{|l|}{$\mathrm{PA}-\mathrm{TiO}_{2}$ glass } \\
\hline $\mathrm{PA}+\mathrm{TiO}_{2}$ glass & 4.1 & 13.5 & 9.8 \\
\hline Aluminium & 2.3 & 7.3 & 5.5 \\
\hline Stainless Steel & 3.5 & 11.9 & 8.7 \\
\hline \multirow[t]{2}{*}{$\begin{array}{l}\text { Viral dynamics parameters } \\
\text { common to all materials }\end{array}$} & $V_{0}\left(\right.$ RNA copies. $\left.\mathrm{mL}^{-1}\right)$ & $c\left(d^{-1}\right)$ & $\pi(\%)$ \\
\hline & 5.89 & 0.0038 & 0.67 \\
\hline
\end{tabular}

${ }^{1}$ Classic glass, Acrylic glass and non photo-activated $\mathrm{TiO}_{2}$ coated glass $\left(\mathrm{PA}-\mathrm{TiO}_{2}\right.$ glass) had similar kinetics and were considered a single group for the statistical analysis, as they presented similar loss rates of virus infectivity.

\section{Discussion}

In this study, significant differences were observed in the persistence of viral infectivity of the causative agent of the COVID-19 deposited in the form of small droplets on non-porous materials. Our data indicate that photo-activated $\mathrm{TiO}_{2}$ coated glass together with aluminium and stainless steel shorten the half-life of infectious SARS-CoV-2 when 
compared to reference surfaces. The soundness of the approach developed here relies on data interpretation considering viral infectivity together with the viral genomic load over time. It emphasizes the limitations of studies claiming to characterize COVID-19 transmission by only reporting traces of viral nucleic acid $[9,10]$.

The mechanisms underlying viral inactivation by aluminium remains unclear. Sizun, J. and collaborators reported a rapid loss of viral infectivity of HCV-OC43 (3 h) and HCV-229E (6 h) after drying on an aluminium surface [20]. Recently Hassan, J. et al. compared etched nanostructure aluminium carriers' performance against smooth aluminium 6063 alloy carriers. They were exposed to $1 \times 10^{3} \mathrm{TCID}_{50}$ in a $10 \mu \mathrm{L}$ droplet of SARS-CoV-2 at room temperature [21]. Remarkably smooth controls exhibit a highly similar decay infectivity behavior in the present assay and in the study carried out by Hassan and collaborators [21]. After $24 \mathrm{~h}$ the decay was accentuated, and no viral infectivity was detected at $48 \mathrm{~h}$ postinoculation.

Several studies report the antiviral effect of $\mathrm{TiO}_{2}$ coatings in viral models such as influenza, human coronavirus NL-63 and bovine respiratory coronavirus [14-16]. The $\mathrm{TiO}_{2}$ photocatalyst provides some advantages such as the strong photo-oxidation capacity, a broad antiviral spectrum, and the possibility of supporting the catalyst on various types of inert matrices $[13,22,23]$. The current $\mathrm{TiO}_{2}$ deposition method-CVD during glass manufacturing — confers sustainable performance of the $\mathrm{TiO}_{2}$ thin film over time, and a strong bonding with the glass matrix, which impedes the release of particles to the environment [17]. Here we proved the antiviral capacity $\mathrm{TiO}_{2}$ directly against SARS-CoV-2, further evaluation for the application on front line scenarios such as hospitals, nursing homes and areas of heavy pedestrian traffic, where self-cleaning surfaces in building materials, equipment, or air-conditioning can help to mitigate indirect fomites transmission paths of SARS-CoV-2 and other nosocomial viral infections [12].

Photocatalytic inactivation of viruses by $\mathrm{TiO}_{2}$ begins by irradiating the semiconductor with UV light with a greater band gap energy of $3.2 \mathrm{eV}$, resulting in an electron-hole pair leaving a free electron in the conduction band and a hole in the valence band. The electron holes react with water molecules or hydroxide ions, forming hydrogen peroxide molecules or hydroxyl radicals, leading to peroxidation of envelope phospholipids and viral proteins. Eventually, the nucleic acid is damaged as well [22,24]. The second photochemical reaction that $\mathrm{TiO}_{2}$ undergoes is a transient modification in wettability, becoming hydrophilic at first and gradually reverting to a more hydrophobic state [22]. By using a pre-irradiation scheme, the current setting clearly discriminates the antiviral activity due to the material from the direct effect of UV light on viral particles. In previous works involving $\mathrm{TiO}_{2}$ thin films or $\mathrm{TiO}_{2}$ nanoparticles, the antiviral properties mediated by the materials were not distinguished as the UV irradiation schemes were continuous [14-16]. Even the reactive oxygen species production is not constant, and the phenomenon of an increase in the hydrophobicity state is progressively reverted in this pre-irradiation scheme; it triggers efficient photo-activation of the material leading to significant antiviral properties.

Our data match that of van Doremalen et al. regarding viral persistence in contact with an acrylic glass. While they estimated a half-life of $6.8 \mathrm{~h}$, a half-life of $6.9 \mathrm{~h}$ was measured in our conditions. However, several concerns were raised regarding experimental designs with either non-accurate viral loads or unstandardized biological matrixes, making it harder to reconcile persistence times ranging from 3 to 28 days $[2,5,7,8]$. It is noteworthy that the matrix, the droplet size, and the elution procedure might be further improved to mimic real-life conditions.

Bueckert and collaborators [25] discussed the factors influencing viral stability outside the host, which involve environmental parameters (temperature, relative humidity, UV light, airflow), inoculum matrix composition (saliva, mucus, proteins, salts, surfactant), the virion's intrinsic properties, and the droplet land surface physicochemical properties. Furthermore, they exposed a wide range of limitations and challenges that allow misinterpretation of current and previous works and impaired reaching definitive conclusions. 
Therefore, efforts should reach reference guidelines, that better reflect the reality of indirect transmission by fomites.

Author Contributions: Conceptualization and investigation: B.M., L.B. and D.C.; performed the experiments: L.B. and D.C.; data analysis: G.L. and J.G.; writing—original draft preparation: L.B., B.M., G.L., J.-C.L., B.V. and J.G.; writing-review and editing: L.B., J.-C.L., B.V., J.G. and B.M.; supervision: B.M., J.G., J.-C.L. and B.V. All authors have read and agreed to the published version of the manuscript.

Funding: This work was funded by the SANA (SArs-CoV-2 in NAmur) research initiative at the University of Namur and a research grant from the FNRS (Urgent Research Credit-40002718). AGC Glass Europe, the manufacturer of two materials tested in this study, provided an unrestricted grant to Université de Namur and the Fondation AP-HP.

Institutional Review Board Statement: Not applicable.

Informed Consent Statement: Not applicable.

Data Availability Statement: Not applicable.

Conflicts of Interest: The findings in this study are those of the authors. Names of specific manufacturers or products are included for public health and informational purposes; inclusion does not imply endorsement of the vendors or manufacturers. Guillaume Lingas received consulting fees from AGC. The other authors have no conflict of interest to declare with the current work. AGC had no role in the data collection and analysis, data interpretation and writing of the report.

\section{References}

1. Ghinai, I.; McPherson, T.D.; Hunter, J.C.; Kirking, H.L.; Christiansen, D.; Joshi, K.; Rubin, R.; Morales-Estrada, S.; Black, S.R.; Pacilli, M.; et al. First Known Person-to-Person Transmission of Severe Acute Respiratory Syndrome Coronavirus 2 (SARS-CoV-2) in the USA. Lancet Lond. Engl. 2020, 395, 1137-1144. [CrossRef]

2. Van Doremalen, N.; Bushmaker, T.; Morris, D.H.; Holbrook, M.G.; Gamble, A.; Williamson, B.N.; Tamin, A.; Harcourt, J.L.; Thornburg, N.J.; Gerber, S.I.; et al. Aerosol and Surface Stability of SARS-CoV-2 as Compared with SARS-CoV-1. N. Engl. J. Med. 2020, 382, 1564-1567. [CrossRef]

3. Bahl, P.; de Silva, C.M.; Chughtai, A.A.; MacIntyre, C.R.; Doolan, C. An Experimental Framework to Capture the Flow Dynamics of Droplets Expelled by a Sneeze. Exp. Fluids 2020, 61, 176. [CrossRef]

4. Transmission of SARS-CoV-2: Implications for Infection Prevention Precautions. Available online: https://www. who.int/publications-detail-redirect/modes-of-transmission-of-virus-causing-covid-19-implications-for-ipc-precautionrecommendations (accessed on 18 December 2020).

5. Kasloff, S.B.; Leung, A.; Strong, J.E.; Funk, D.; Cutts, T. Stability of SARS-CoV-2 on Critical Personal Protective Equipment. Sci. Rep. 2021, 11, 984. [CrossRef]

6. Biryukov, J.; Boydston, J.A.; Dunning, R.A.; Yeager, J.J.; Wood, S.; Reese, A.L.; Ferris, A.; Miller, D.; Weaver, W.; Zeitouni, N.E.; et al. Increasing Temperature and Relative Humidity Accelerates Inactivation of SARS-CoV-2 on Surfaces. mSphere 2020, 5. [CrossRef] [PubMed]

7. Riddell, S.; Goldie, S.; Hill, A.; Eagles, D.; Drew, T.W. The Effect of Temperature on Persistence of SARS-CoV-2 on Common Surfaces. Virol. J. 2020, 17, 145. [CrossRef] [PubMed]

8. Chin, A.W.H.; Chu, J.T.S.; Perera, M.R.A.; Hui, K.P.Y.; Yen, H.-L.; Chan, M.C.W.; Peiris, M.; Poon, L.L.M. Stability of SARS-CoV-2 in Different Environmental Conditions. Lancet Microbe 2020, 1, e10. [CrossRef]

9. Wu, S.; Wang, Y.; Jin, X.; Tian, J.; Liu, J.; Mao, Y. Environmental Contamination by SARS-CoV-2 in a Designated Hospital for Coronavirus Disease 2019. Am. J. Infect. Control 2020, 48, 910-914. [CrossRef]

10. Guo, Z.-D.; Wang, Z.-Y.; Zhang, S.-F.; Li, X.; Li, L.; Li, C.; Cui, Y.; Fu, R.-B.; Dong, Y.-Z.; Chi, X.-Y.; et al. Aerosol and Surface Distribution of Severe Acute Respiratory Syndrome Coronavirus 2 in Hospital Wards, Wuhan, China, 2020. Emerg. Infect. Dis. 2020, 26, 1583-1591. [CrossRef] [PubMed]

11. Coupeau, D.; Burton, N.; Lejeune, N.; Loret, S.; Petit, A.; Pejakovic, S.; Poulain, F.; Bonil, L.; Trozzi, G.; Wiggers, L.; et al. SARS-CoV-2 Detection for Diagnosis Purposes in the Setting of a Molecular Biology Research Lab. Methods Protoc. 2020, 3, 59. [CrossRef] [PubMed]

12. Pemmada, R.; Zhu, X.; Dash, M.; Zhou, Y.; Ramakrishna, S.; Peng, X.; Thomas, V.; Jain, S.; Nanda, H.S. Science-Based Strategies of Antiviral Coatings with Viricidal Properties for the COVID-19 Like Pandemics. Materials 2020, 13, 4041. [CrossRef]

13. Imani, S.M.; Ladouceur, L.; Marshall, T.; Maclachlan, R.; Soleymani, L.; Didar, T.F. Antimicrobial Nanomaterials and Coatings: Current Mechanisms and Future Perspectives to Control the Spread of Viruses Including SARS-CoV-2. ACS Nano 2020, 14, 12341-12369. [CrossRef] [PubMed] 
14. Nakano, R.; Ishiguro, H.; Yao, Y.; Kajioka, J.; Fujishima, A.; Sunada, K.; Minoshima, M.; Hashimoto, K.; Kubota, Y. Photocatalytic Inactivation of Influenza Virus by Titanium Dioxide Thin Film. Photochem. Photobiol. Sci. Off. J. Eur. Photochem. Assoc. Eur. Soc. Photobiol. 2012, 11, 1293-1298. [CrossRef]

15. Yoshizawa, N.; Ishihara, R.; Omiya, D.; Ishitsuka, M.; Hirano, S.; Suzuki, T. Application of a Photocatalyst as an Inactivator of Bovine Coronavirus. Viruses 2020, 12, 1372. [CrossRef] [PubMed]

16. Khaiboullina, S.; Uppal, T.; Dhabarde, N.; Subramanian, V.R.; Verma, S.C. Inactivation of Human Coronavirus by Titania Nanoparticle Coatings and UVC Radiation: Throwing Light on SARS-CoV-2. Viruses 2020, 13, 19. [CrossRef] [PubMed]

17. EN 1096-2:2012-Glass in Building-Coated Glass-Part 2: Requirements and Test Methods for Class A, B and S Coatings. Available online: https:/ / standards.iteh.ai/catalog/standards/cen/9f57ae4a-bee6-40cb-8af1-bb72f200d505/en-1096-2-2012 (accessed on 9 March 2021).

18. Lavielle, M. Mixed Effects Models for the Population Approach: Models, Tasks, Methods and Tools; Chapman and Hall/CRC Press: Boca Raton, FL, USA, 2014; ISBN 978-0-429-15718-9.

19. Schwarz, G. Estimating the Dimension of a Model. Ann. Stat. 1978, 6, 461-464. [CrossRef]

20. Sizun, J.; Yu, M.W.; Talbot, P.J. Survival of Human Coronaviruses 229E and OC43 in Suspension and after Drying Onsurfaces: A Possible Source Ofhospital-Acquired Infections. J. Hosp. Infect. 2000, 46, 55-60. [CrossRef] [PubMed]

21. Hasan, J.; Pyke, A.; Nair, N.; Yarlagadda, T.; Will, G.; Spann, K.; Yarlagadda, P.K.D.V. Antiviral Nanostructured Surfaces Reduce the Viability of SARS-CoV-2. ACS Biomater. Sci. Eng. 2020, 6, 4858-4861. [CrossRef] [PubMed]

22. Schneider, J.; Matsuoka, M.; Takeuchi, M.; Zhang, J.; Horiuchi, Y.; Anpo, M.; Bahnemann, D.W. Understanding TiO2 Photocatalysis: Mechanisms and Materials. Chem. Rev. 2014, 114, 9919-9986. [CrossRef] [PubMed]

23. Evans, P.; Sheel, D.W. Photoactive and Antibacterial $\mathrm{TiO}_{2}$ Thin Films on Stainless Steel. Surf. Coat. Technol. 2007, 201, 9319-9324. [CrossRef]

24. Bogdan, J.; Zarzyńska, J.; Pławińska-Czarnak, J. Comparison of Infectious Agents Susceptibility to Photocatalytic Effects of Nanosized Titanium and Zinc Oxides: A Practical Approach. Nanoscale Res. Lett. 2015, 10, 1023. [CrossRef] [PubMed]

25. Bueckert, M.; Gupta, R.; Gupta, A.; Garg, M.; Mazumder, A. Infectivity of SARS-CoV-2 and Other Coronaviruses on Dry Surfaces: Potential for Indirect Transmission. Mater. Basel Switz. 2020, 13, 5211. [CrossRef] 